\title{
The Binding of Metallic Cations to Poly(Styrene Sulphonate) \\ Polymers and Copolymers
}

\author{
Miguel G. Neumann*, Luciana Tiberti and Maira R. Rodrigues \\ Instituto de Química de São Carlos, Universidade de São Paulo, C.P. 780 \\ 13560-970 São Paulo - SP, Brazil
}

Received: October 31, 1994; February 12, 1994

\begin{abstract}
Foram determinadas as energias de ligação de 11 íons metálicos a poli(estirenossulfonato) e seus copolímeros com metil metacrilato, usando uma modificação do método de supressão de sondas usado para micelas. As constantes de equilíbrio para a ligação a poli(estirenossulfonato) totalmente sulfonado variam entre 177 para $\mathrm{Mn}^{2+}$ e 4.4 para $\mathrm{Ag}^{+}$, em termos de ligação por equivalente de grupo sulfonato. A ordem das constantes é a mesma encontrada para as micelas de SDS, indicando que as interações são do mesmo tipo. O aumento do peso molecular dos polímeros não afeta significativamente as constantes de ligação. Por outro lado, a diminuição da densidade de carga ao longo da cadeia aumenta o valor dessas constantes. Foram determinadas as constantes críticas de agregação dos polieletrólitos, que dependem da densidade de carga. Para o polímero totalmente sulfonado esse valor está em torno de $0.01 \mathrm{eq} / \mathrm{L}$, enquanto para os polímeros com $40 \%$ e $18 \%$ de monômeros sulfonados essa concentração cai para 0.002 e $0.001 \mathrm{eq} / \mathrm{L}$, respectivamente. Os mesmos valores foram obtidos a partir de estudos de supressão de pireno e de medidas viscosimétricas.
\end{abstract}

The binding energies of 11 metallic ions to poly(styrene sulphonate) and its copolymers with methyl methacrylate have been determined using a modification of the probe quenching method used for micelles. The equilibrium constants for the binding to totally sulphonated poly(styrene sulphonate) range from 177 for $\mathrm{Mn}^{2+}$ to 4.4 for $\mathrm{Ag}^{+}$, in terms of binding per sulphonate group equivalent. The order of the constants is the same as for SDS micelles, indicating that the interactions are of the same type. Increasing the molecular weight of the polymers does not affect the binding constants significatively. On the other hand, a decrease of the charge density along the chain increases the value of these constants. Critical aggregation concentrations for the polyelectrolytes were determined and depend on the charge density. For the polymer with sulphonate groups on nearly all monomers that value is around $0.01 \mathrm{eq} / \mathrm{L}$, whereas for the polymers with $40 \%$ and $18 \%$ of sulphonated monomers this concentration falls to 0.002 and $0.001 \mathrm{eq} / \mathrm{L}$, respectively. The same values were obtained from pyrene quenching and viscosity measurement studies.

Keywords: polyelectrolytes, critical aggregation concentration, probe quenching, binding constants

\section{Introduction}

Polyelectrolytes are macromolecular compounds that when dissolved in water, or other polar solvents, ionise partially or totally, depending on the strength of the ionisable groups. When the polyelectrolytes do not dissociate completely, or when they are non-ionisable monomers in the chain, these compounds may form hydrophobic domains similar to those found in solutions of surfactants. The interest in polyelectrolytes is vast. It ranges from their industrial use as thickeners for paints, flocculating agents in sewage treatment and dispersing compounds for oil spills, to their synthetic use as "micellar catalysts"1-3. Another point that makes the study of polyelectrolytes very important is that they are very good models for evaluating the properties macromolecular biomolecules like nucleic acids, polysaccharides and others ${ }^{4}$.

Pyrene, due to its especial photophysical properties, like having emission spectra which depend on the medium where it is immersed, as well as to its rather long emission 
lifetime $(\sim 450 \mathrm{~ns})^{1,5}$, has been used largely to study the behaviour of polyelectrolytes and other microheterogeneous systems ${ }^{1,6-9}$.

Although many investigations have been performed on the properties of the hydrophobic domains formed by the dissolution of polyelectrolytes in aqueous solutions, very little is known about the binding properties of different compounds to that domains. The binding of different types of dyes to poly(styrene sulphonate) has been studied quite extensively by the group of Vitagliano ${ }^{10}$. The adsorption of Methylene Blue on poly(styrene sulphonate) and poly(vinyl sulphate) was studied by Shirai and cowork$\mathrm{ers}^{11}$. Both groups were mainly interested in the induced dye aggregation phenomena. We studied the induced aggregation of Methylene Blue and Acridine Orange on poly(styrene sulphonate) and carboxymethylcellulose ${ }^{12}$, as well as the adsorption of a series of dyes on poly(styrene sulphonate) in order to determine the group contributions to the adsorption free energies of these dyes ${ }^{13}$.

Except for the work of Park et al. ${ }^{14}$, who determined the binding constant of copper ions to poly(styrene sulphonate) and our recently published work on the binding of some ions and neutral molecules to the same polyelectrolyte ${ }^{15}$, no data exists on the binding properties of ions to the microheterogeneous domains formed by macromolecules. Therefore, we want to report in this paper the binding constants of several metallic ions to poly(styrene sulphonate) and its copolymers. The influence of the molecular mass of the polymers and the charge distribution on these constants was also determined. Critical aggregation constants, at which the hydrophobic microdomains start to form were determined for each polyelectrolyte.

\section{Experimental}

The fluorescence quenching of pyrene $\left(1 \times 10^{-6} \mathrm{M}\right)$ was studied statically using an Aminco-Bowman J4 spectrofluorimeter, at $25 \pm 1{ }^{\circ} \mathrm{C}$. Viscosities were determined on an Ubbelohde Viscoboy 2 viscosimeter.

The polyelectrolytes that were used were poly(styrene sulphonate) $90 \%$ sulphonated, MW $7.0 \times 10^{4}$ (PSS90, Aldrich); poly(styrene sulphonate) $85 \%$ sulphonated, $\mathrm{MW}$ $2.1 \times 10^{5}$ (PSS85, Aldrich); a synthesised poly(methyl methacrylate-co-styrene sulphonate) copolymer $45 \%$ sulphonated, MW $1.4 \times 10^{5}$ (PSS40); and a synthesised poly(methyl methacrylate-co-styrene sulphonate) copolymer $18 \%$ sulphonated, MW $1.0 \times 10^{5}$ (PSS18). The synthesis of the copolymers was done by polymerizing together the appropriate amounts of the monomers using AIBN as initiator in a degassed solution at $60^{\circ} \mathrm{C}$.

Pyrene (Aldrich) was recrystallized from benzene. The salts of the metallic ions were $\mathrm{CeCl}_{3}\left(\mathrm{C}\right.$. Erba), $\mathrm{Pb}\left(\mathrm{NO}_{3}\right)_{2}$ (Riedl), $\mathrm{CuSO}_{4} .5 \mathrm{H}_{2} \mathrm{O}$ (C. Erba), $\mathrm{NiSO}_{4} \cdot 6 \mathrm{H}_{2} \mathrm{O}$ (Caal), $\mathrm{CsCl}$ (C. Erba), $\mathrm{CoCl}_{2} \cdot 6 \mathrm{H}_{2} \mathrm{O}$ (C. Erba), $\mathrm{AgNO}_{3}$ (Merck), $\mathrm{CrCl}_{3} .6 \mathrm{H}_{2} \mathrm{O}$ (Reagen), $\mathrm{MnSO}_{4} \cdot \mathrm{H}_{2} \mathrm{O}$ (Synth), and
$\mathrm{FeSO}_{4} .7 \mathrm{H}_{2} \mathrm{O}$ (Synth). Ionic strength was kept constant by addition of $\mathrm{NaCl}$.

\section{Results and Discussion}

The quenching of the fluorescence of pyrene by metallic ions in the presence of increasing amounts of polyelectrolyte, gave Stern-Volmer plots similar to that shown in Fig. 1 for $\mathrm{Co}^{2+}$ in the presence of PSS90. In general, the plots show a decreasing quenching efficiency when the amount of polyelectrolyte is increased, indicating that the probe migrates to the more hydrophobic domains which are formed in those conditions. In those regions it will be better protected from the quencher. In most cases, at sufficiently high quencher concentrations the plots curve down tending to a plateau. This is interpreted as a saturation of the sites near to probe, so that the additional quencher ions will be located farther away from the hydrophobic sites, having a lower quenching efficiency.

The data obtained in this way has been replotted according to an adaptation of the method of Encinas and Lissi ${ }^{16}$, in which the concentration of micelles is replaced by the equivalent concentration of sulphonate groups ${ }^{15}$. This approximation considers that the amount of hydrophobic domains formed by the polyelectrolytes is proportional to the number of sulphonate groups present in the polyelectrolyte solution. The plot in Fig. 2 is obtained from the experimental data in Fig. 1 using this method. A similar behaviour was observed for all the other systems.

Two regions can be clearly identified in that plot. For higher sulphonate concentrations, the experimental points fall on a line from which the binding constants of the quenchers can be calculated by using

$$
[\mathrm{Q}]_{\mathrm{r}}=\overline{\mathrm{n}} / \mathrm{K}+\overline{\mathrm{n}} \cdot\left[\mathrm{S}^{-}\right]
$$

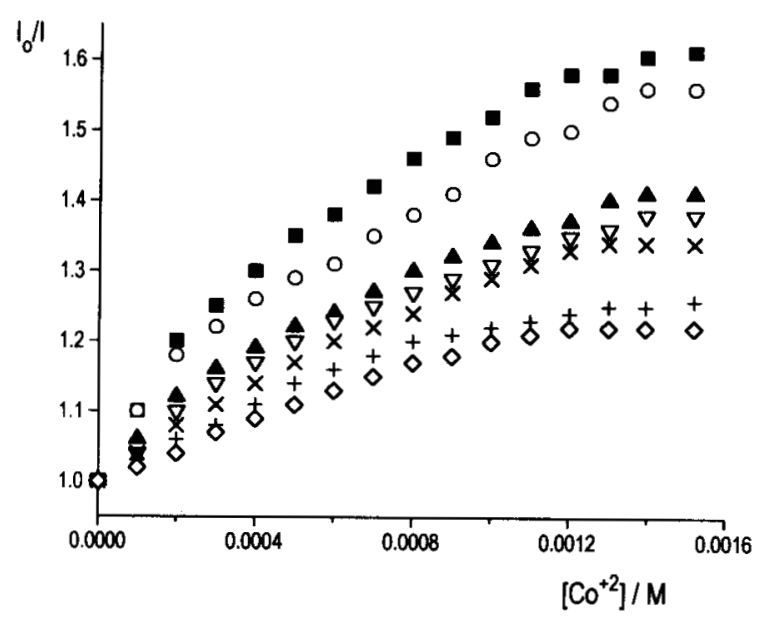

Figure 1. Stern-Volmer plots for the quenching of pyrene $\left(1 \times 10^{-5} \mathrm{M}\right)$ by $\mathrm{Co}^{2+}$ ions in the presence of PSS90. Concentrations of PSS90: (口) 0.003; (O) $0.005 ;(\mathbf{A}) 0.008 ;(\nabla) 0.010 ;(\mathbf{x}) 0.020 ;(+) 0.040 ;(\diamond) 0.060 \mathrm{eq} / \mathrm{L}$. 


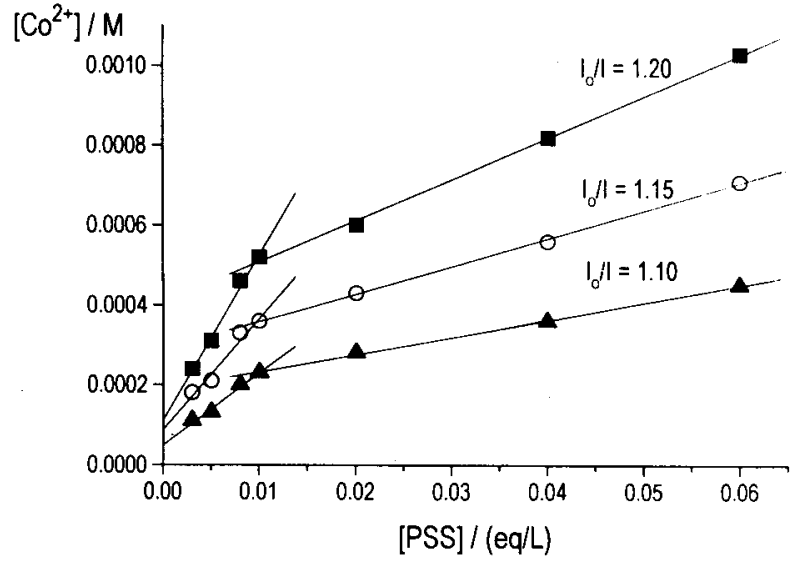

Figure 2. Modified Encinas and Lissi plot for the quenching of pyrene by $\mathrm{Co}^{2+}$ in the presence of PSS90.

where $[Q]_{\mathrm{r}}$ represents the quencher concentration for getting a quenching ratio $r$, at sulphonate group concentration $\left[\mathrm{S}^{-}\right] ; \bar{n}$ is the 'occupancy' of the hydrophobic domains; and $\mathrm{K}$ is the binding constant for the quencher $\mathrm{Q}$.

For lower concentrations of the polyelectrolyte the observed behaviour could be approached by another line with a steeper slope and a lower zero-extrapolation. However, these lines did not give consistent values for $\mathrm{K}$ when Eq. 1 was applied to them.

The polyelectrolyte concentration at which both lines cut is the same for each polyelectrolyte, independent of the quencher used. Therefore, it should correspond to a property of the polyelectrolyte itself. Furthermore, plots of the relative viscosity show a change in the slope around the same concentration (Fig. 3). This change of behaviour is attributed to a change in the conformation of the polymer chain, which starts to aggregate at that concentrations. This

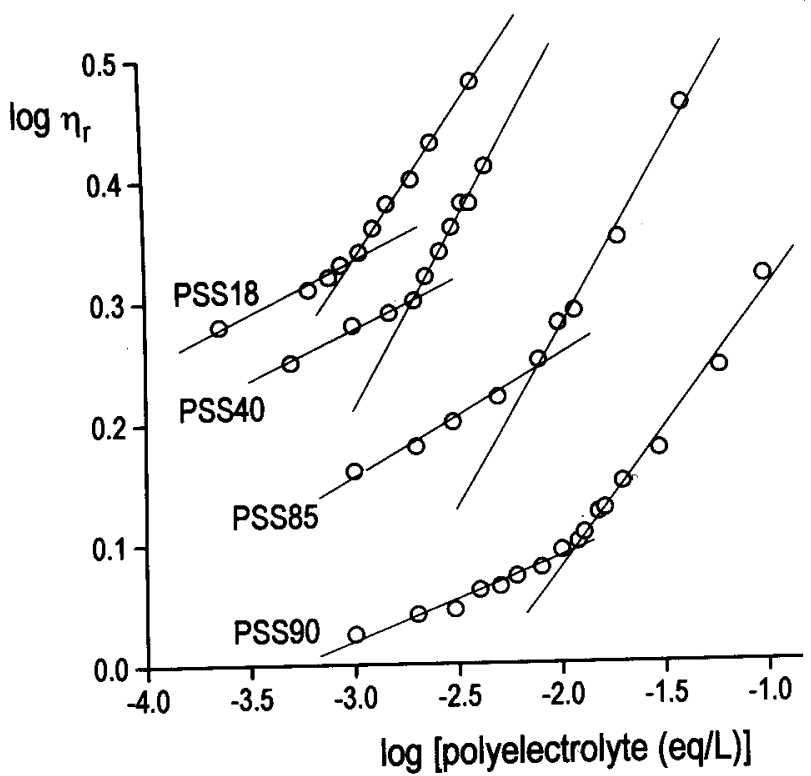

Figure 3. Relative viscosity of the polyelectrolytes. aggregation must be an interchain interaction, as the same results are obtained from viscosity and quenching experiments. The effect of an intrachain, or even interchain, interaction induced by cations with multiple charges can be discarded because the change of slope is also observed with monovalent ions and neutral molecules ${ }^{15}$.

It can be observed from Table 1 that the CAC values do not depend on the molecular weight of the polymer, as similar values were obtained for PSS90 and PSS85 which differ by a factor 3 in their MW (the difference in the charge density can be considered marginal). On the other hand, the charge density on the polymer seems to have a more significant role on the CAC. It can be seen that for the copolymer containing $40 \%$ of sulphonate groups the CAC is nearly 5 times smaller, whereas for PSS1 8 it is 10 times smaller than for the almost totally ionised PSS85 and PSS90. This is an indication that the presence of noncharged monomers increases the interaction between chains, lowering the concentration at which the hydrophobic domains start their formation.

The binding constants of the metallic ions to the polyelectrolytes are shown in Table 2 . It can be seen that these constants follow a trend similar to that found for the

Table 1. Critical aggregation concentrations (in eq/L) for polyelectrolytes obtained from pyrene quenching and viscosity measurements.

\begin{tabular}{lcl}
\hline \multicolumn{1}{c}{ Polyelectrolyte } & pyrene quenching & viscosity \\
\hline PSS90 & $0.009-0.012$ & 0.012 \\
PSS85 & $0.009-0.012$ & 0.009 \\
PSS40 & $0.0020-0.021$ & 0.0020 \\
PSS18 & $0.0009-0.011$ & 0.0010 \\
\hline
\end{tabular}

Table 2. Binding constants of metallic ions to anionic polyelectrolytes and SDS.

\begin{tabular}{lccccc}
\hline \multicolumn{5}{c}{ Polyelectrolyte (eq/L) } & \\
\cline { 1 - 5 } \multicolumn{1}{c}{ Ion } & PSS90 & PSS85 & PSS40 & PSS18 & \\
\cline { 1 - 5 } $\mathrm{Mn}^{+2}$ & $177 \pm 20$ & & & & $126000^{\mathrm{c}}$ \\
$\mathrm{Ce}^{+3}$ & $160 \pm 11$ & & & & \\
$\mathrm{~Pb}^{2+}$ & $93 \pm 7$ & & & $697 \pm 49$ & $27700^{\mathrm{b}}$ \\
$\mathrm{Cu}^{+2}$ & $40 \pm 3^{\mathrm{a}}$ & $38 \pm 3$ & $194 \pm 10$ & & $11000^{\mathrm{c}}$ \\
$\mathrm{Fe}^{+2}$ & $35 \pm 4$ & & & & \\
$\mathrm{Ni}^{+2}$ & $33 \pm 2^{\mathrm{a}}$ & & $111 \pm 8$ & $225 \pm 16$ & $10900^{\mathrm{b}}$ \\
$\mathrm{Cs}^{+}$ & $27 \pm 2$ & $33 \pm 2$ & $94 \pm 7$ & & $10000^{\mathrm{b}}$ \\
$\mathrm{Co}^{+2}$ & $24 \pm 2$ & $30 \pm 2$ & $67 \pm 7$ & $201 \pm 14$ & $8700^{\mathrm{b}}$ \\
$\mathrm{Cr}^{+3}$ & & & & $162 \pm 11$ & $5900^{\mathrm{b}}$ \\
$\mathrm{Tl}^{+}$ & $15 \pm 1^{\mathrm{a}}$ & & & & $3800^{\mathrm{b}}$ \\
$\mathrm{Ag}^{+}$ & $4.4 \pm 0.3$ & $4.1 \pm 0.3$ & & & $1300^{\mathrm{d}}$ \\
\hline
\end{tabular}

(a) Ref. 15; (b) Ref. 7; (c) Ref. 17; (d) Ref. 18. 
binding of the same ions to SDS micelles, also shown in the table. The values of the binding constants are expressed considering the binding per unit sulphonate group, i.e., taking the reference state for the polymer binding sites as one equivalent per litre. The binding constants follow the order

$\mathrm{K}_{\mathrm{PSS} 18}>\mathrm{K}_{\mathrm{PSS} 40}>\mathrm{K}_{\mathrm{PSS} 85} \approx \mathrm{K}_{\mathrm{PSS} 90}$

This shows that the binding constants (per unit charge) are higher when the charge density is lower. The cations that are in the domain of the polyelectrolyte will interact with the anionic sites of the polyelectrolyte. A more compact structure, as expected for the more hydrophobic copolymers, will permit a better interaction with various sites, increasing the overall electrostatic interaction. On the more extended polyelectrolytes these interactions will be less important as there is more separation between the charges. A comparison of the values for the binding strength per unit anionic charge on SDS shows that they can be situated between those for PSS 18 and PSS40, indicating that the binding mechanism is the same for micelles and polyelectrolytes, and the cooperativity of the electrostatic interactions are also similar.

In Table 3 are shown the binding free energies, and the distances between the ions and the center of negative charge, assuming that all that energy has electrostatic origin. The distances suggest that there may be some intercalation of the multivalent ions between the negatively charged centers of the polyelectrolyte. No clear relationship can be found between these distances and the charges on the ions. Studies with anionic micellar systems showed that there is neither a dependence with the ratio between the charge and the ionic radii, $\mathrm{Z} / \mathrm{r}^{17}$, or even the hydrated ionic radii.

\section{Acknowledgments}

Financial support by FAPESP (Project 91/0480-1), PADCT-FINEP (Project 65-92-0063-00) and CNPq is

Table 3. Binding free energies (in $\mathrm{kcal} / \mathrm{mol}$ ) and calculated distances (in $\AA$ ) for the interaction of metallic ions with anionic polyelectrolytes.

\begin{tabular}{lccccccccc}
\hline \multicolumn{10}{c}{ Polyelectrolyte } \\
\hline Ion & \multicolumn{1}{c}{ PSS90 } & \multicolumn{2}{c}{ PSS85 } & \multicolumn{2}{c}{ PSS40 } & \multicolumn{2}{c}{ PSS18 } \\
\hline & $\Delta \mathrm{G}$ & $\mathrm{d}$ & $\Delta \mathrm{G}$ & $\mathrm{d}$ & $\Delta \mathrm{G}$ & $\mathrm{d}$ & $\Delta \mathrm{G}$ & $\mathrm{d}$ \\
\hline $\mathrm{Ce}^{+3}$ & 3.0 & 1.4 & & & & & & \\
$\mathrm{~Pb}^{2+}$ & 2.7 & 1.6 & & & & & 3.9 & 1.1 \\
$\mathrm{Cu}^{+2}$ & 2.2 & 1.9 & 2.2 & 1.9 & & & & \\
$\mathrm{Ni}^{+2}$ & 2.1 & 2.0 & & & 2.8 & 1.5 & 3.2 & 1.3 \\
$\mathrm{Cs}^{+}$ & 2.0 & 2.1 & 2.1 & 2.0 & 2.7 & 1.5 & & \\
$\mathrm{Co}^{+3}$ & 1.9 & 2.2 & 2.0 & 2.1 & & & 3.1 & 1.3 \\
$\mathrm{Cr}^{+3}$ & & & & & & & 3.0 & 1.4 \\
$\mathrm{Tl}^{+}$ & 1.6 & 2.5 & & & & & & \\
$\mathrm{Ag}^{+}$ & 0.9 & 4.6 & 0.8 & 4.9 & & & & \\
\hline
\end{tabular}

gratefully acknowledged. M.R.R. thanks FAPESP for a graduate fellowship and L.T. thanks CNPq for an undergraduate fellowship.

\section{References}

1. K. Kalyanasundaram, Photochemistry in Microheterogeneous System (Academic Press, New York, 1987).

2.H.H. Fendler, Membrane Mimetic Chemistry (Wiley, New York, 1982).

3. Y. Itoh, Y. Morishima and S. Nozakura, Photochem. Photobiol. 39, 603 (1984); J. W. Otvos, T.E. Casti and M. Calvin, Sci. Pap. Inst. Phys. Chem. Res. 78, 129 (1984); M. Wolsczak and J.K. Thomas, Radiat. Phys. Chem. 38, 155 (1991); Y. Morishima, M. Tsuji, M. Kamachi and K. Hatada Macromolecules 25, 4406 (1992).

4. M. Mandel, Polyelectrolytes, In: Encyclopaedia of Polymer Science and Engineering, (2nd. ed., Wiley, 1988), Vol. 11.

5. T.A. Wielema and J.B.F.N. Engberts, Eur. Polym. J. 26, 1065 (1990); K. Kalyanasundaram and J.K. Thomas, J. Am. Chem. Soc. 99, 2039 (1977).

6.C.L. Zhao, M.A. Winnik, G. Riess and M.D. Croucher, Langmuir 6, 514 (1990); H.D. Burrows, S.J. Formosinho and M.F.J.R. Paiva, J. Photochem. 12, 285 (1980); H.J. Pownall and L.C Smith, Biochemistry 13, 2594 (1974); M.H. Gehlen and F.C. De Schryver, Chem. Rev. 93, 199 (1993); M.G. Neumann and M.J. Tiera, Quim. Nova 16, 280 (1993).

7.J.C. Dederen, M. Van der Auweraer and F.C. De Schryver, J. Phys. Chem. 85, 1198 (1981).

8. N.J. Turro and I.F. Pierola, J. Phys. Chem. 87, 2420 (1983); E. Baumgartner, S.G. Bertolotti, J.J. Cosa, H.E. Gsponer, M. Hamity and C.M. Previtali, J. Colloid Interface Sci. 115, 417 (1987); N.J. Turro and C.J. Chung, Macromolecules 17, 2123 (1984); F. Buyl, A.K. Mesmaeker, A. Tossi and J.M. Kelly, J. Photochem. Photobiol. A: Chem. 60, 27 (1991); D. Meisel and M.S. Matheson, J. Am. Chem. Soc. 99, 6577 (1977).

9. M.J. Tiera, M.G. Neumann, S.G. Bertolotti and C.M. Previtali, J. Macromol. Sci., Pure Appl. Chem. A29, 689 (1992); M.J. Tiera, M.G. Neumann, C.M. Previtali and S.G. Bertolotti, J. Macromol. Sci., Pure Appl. Chem. A31, 439 (1994).

10. V. Vitagliano In: Aggregation Processes in Solution, (E. Wyn-Jones and E. Gornally, eds., Elsevier, Amsterdam, 1983), Ch. 11.

11. M. Shirai, T. Nagatsuka and M. Tanaka, Makromol. Chem. 178, 37 (1977); M. Shirai, T. Nagatsuka and M. Tanaka, J. Polym. Sci., Polym. Chem. Ed. 15, 2083 (1977).

12. M.G. Neumann and N. Hioka, J. Appl. Polym. Sci. 43, 2829 (1987). 
13. M.G. Neumann, F. Gessner and G. de Sena, Dyes Pigm. 20, 255 (1992).

14. J.W.Park, M.-H. Kim, S.H. Ko and Y.H. Paik, J. Phys. Chem. 97, 5424 (1993).

15. M.G. Neumann and M.R. Rodrigues, J. Photochem. Photobiol. A: Chem. 83, 164 (1994).
16. M.V. Encinas and E.A. Lissi, Chem. Phys. Lett. 91, 55 (1982).

17. H. Ziemiecki and W.R. Cherry, J. Am. Chem. Soc. 103, 4479 (1981).

18. F. Grieser and F.C. Taush-Treml, J. Am. Chem. Soc. 102,7258 (1980). 